\title{
Preparation and Utilization of Natural Aloe Vera to Enhance Quality of Mango Fruit
}

\author{
Tamiru Kasaye Atlaw \\ Department of Food Engineering, College of Technology, Debre Berhan University, Debre Berhan, Ethiopia \\ Email address: \\ tamirukasaye514@gmail.com

\section{To cite this article:} \\ Tamiru Kasaye Atlaw. Preparation and Utilization of Natural Aloe Vera to Enhance Quality of Mango Fruit. Journal of Food and Nutrition \\ Sciences. Vol. 6, No. 3, 2018, pp. 76-84. doi: 10.11648/j.jfns.20180603.12
}

Received: June 21, 2018; Accepted: July 12, 2018; Published: August 6, 2018

\begin{abstract}
The main objective of this study was to see the effect of natural Aloe vera gel coating, and combined with citric acid treatments on shelf life and quality of mango during storage. Mango fruit is very perishable in nature and considerable postharvest quality defect is occurred during and after harvest. Postharvest loss on fruits especially mango fruit is common in Ethiopia especially areas like North Shewa Administrative Zone, Shewa Robit, Ethiopia due to hot and humid condition (16.5$31^{\circ} \mathrm{C}$ ) and poor fruit harvesting transporting, handling and storage condition by farmers, wholesalers and consumers. Physicochemical parameters such as weight loss, $\mathrm{pH}$, moisture, titratable acidity and total soluble solids (TSS) of mango fruit was determined at 7 days interval during the storage period. The control fruits started deteriorated before 17 days and only few fruits survived up to 21 days, whereas, shelf life extended to 29 days for majority of aloe vera gel alone and with citric acid coated fruits. At the end of the storage period, uncoated mango fruits showed $22.04 \%$ loss in weight, whereas coated mango fruits with aloe vera gel and combination with citric acid was $8.6 \%$ and $7.6 \%$ by weight loss, respectively. Among the physicochemical parameters, $\mathrm{pH}$ and TSS contents increased significantly $(\mathrm{p} \leq 0.05)$, whereas total weight loss, moisture content and titratable acidity decreased during storage. The present work reveals that potential application of natural aloe vera (Aloe debrana) gel with citric acid coatings for enhancing the postharvest shelf life and maintaining quality of mango fruit.
\end{abstract}

Keywords: Mango, Physico-chemical, Postharvest, Shelf Life, Storage

\section{Introduction}

Consumers around the world demand for food of high quality, without chemical preservatives, and an extended shelf life. Therefore, an increased effort has been made to develop new natural preservatives and antimicrobials [3]. Many storage techniques have been developed to extend the marketing distances and holding periods for commodities after harvest. Different preservation methodologies have been developed.

One method of extending postharvest shelf life is the use of the edible coatings. The coating technology is one of the important and popular techniques used to prolong the shelf life and reduce their wastage. Edible films and coatings have received considerable attention in recent years because of their advantages including use as edible packaging materials over synthetic films. Edible coatings create a modified atmosphere around the fruit by providing a semi permeable barrier to water vapor and gases, and their use offers an attractive alternative to film packaging due to their environmentally friendly characteristic [8]. They are applied directly on the food surface by dipping, spraying or brushing [5].

Aloe vera gel is a novel edible coating for organic fruit storage technology. Aloe vera gel-based edible coatings have been shown to prevent loss of moisture and firmness, control respiratory rate and maturation development, delay oxidative browning and reduce microorganism proliferation in fruits such as table grapes [2] sweet cherries [4] and table grapes [10].

Citric acid (CA) is an anti-browning agent, which prevents polyphenol oxidase (PPO) by suppressing the food $\mathrm{pH}$ and binding the $\mathrm{Cu}^{2+}$ in an active site of PPO to form an inactive component. It has also been widely used in the food industries for controlling the browning. Applying CA as a dipping solution has been reported in postharvest fruits with very satisfactory results for fruits such as longan [9].

Mango fruit is very perishable in nature and considerable postharvest quality defect is occurred during and after 
harvest. Hence, mango fruit is susceptible to postharvest damage, pest and disease attack and considerable yield loss occurs during harvesting, transporting, handling and storage condition. Postharvest major defects on mango fruit may be common in Ethiopia especially at areas like Shewa Robit due to hot and humid condition and poor fruit harvesting and handling by farmers and retail wholesalers. Therefore, this study was aim at the shelf life extension of mango using natural aloe vera gel and citric acid treatment.

\section{Materials and Methods}

\subsection{Raw Material Collection, Transportation and Preparation}

The research materials for this study were Aloe vera leaves

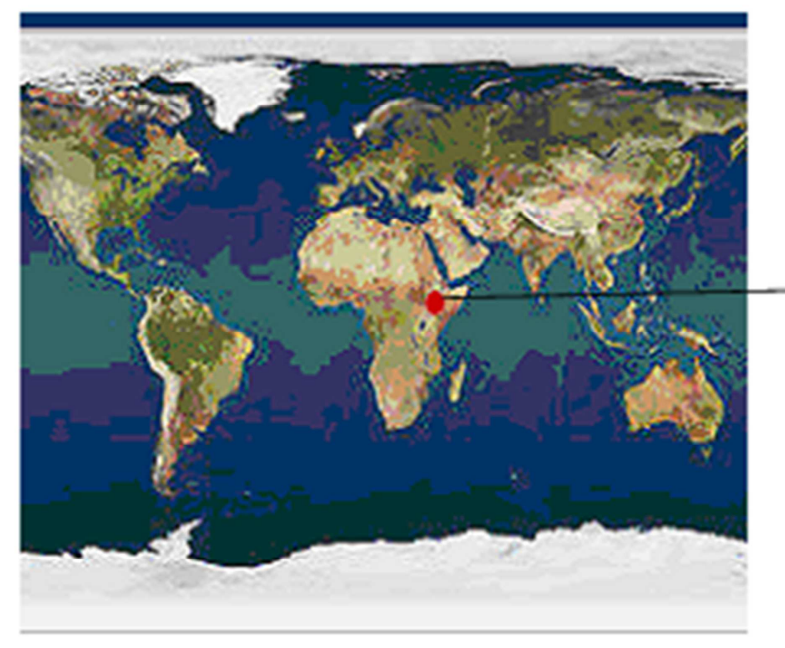

(Aloe debrana), citric acid and Mango fruit (keitt). The fresh leaves of Aloe vera leave was collected and transported from around cha cha place from Debre berhan $17 \mathrm{~km}$.

Mango (keitt) was collected from Shewa Robit integrated research and development site of Debre Berhan University. The site is found North Shewa administrative zone, Shewa Robit, Ethiopia. Shewa Robit is located at about $225 \mathrm{~km}$ North East of Addis Ababa (Figure 1). It is located at $11^{\circ} 55^{\text {, }}$ $\mathrm{N}$ latitude and $37^{\circ} 20^{\prime} \mathrm{E}$ longitude with an elevation of 1280 meters above sea leve. The area has an average annual rainfall of $1007 \mathrm{~mm}$, with short rain between March and April and long rain between June and September, and annual mean minimum and maximum temperatures of 16.5 and $31^{\circ} \mathrm{C}$, respectively.

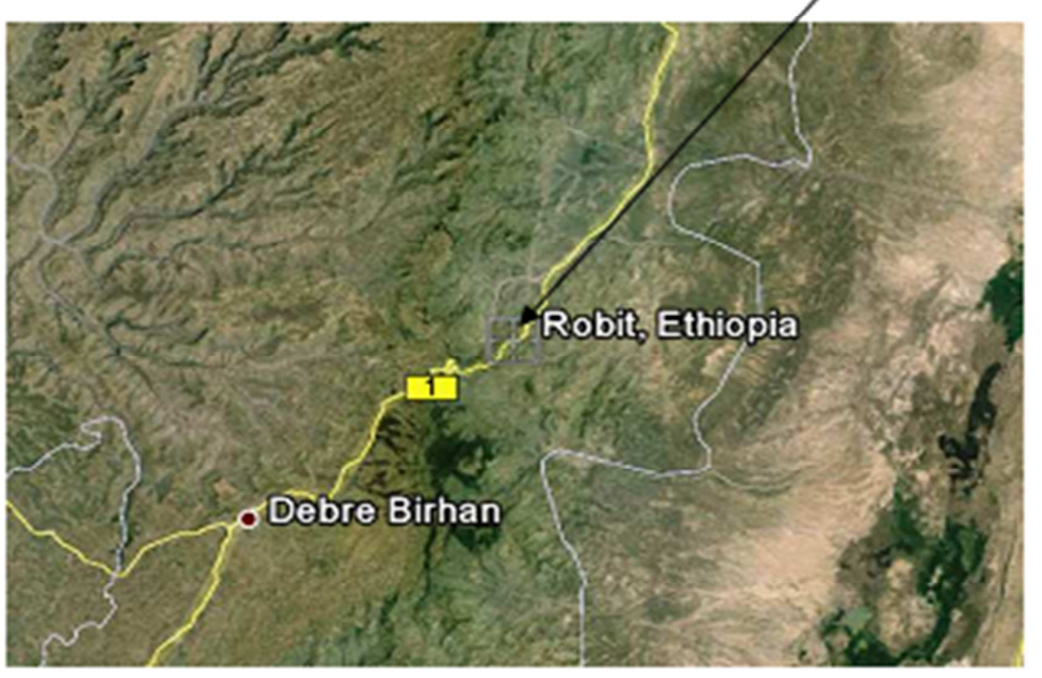

Figure 1. Location of source of Mango Fruit (World Google Maps, June 2014).

The fruit was harvested by hand at hard green stage of maturity (Figure 2). Sample preparation and all treatment measurements were done in Debre berhan University, College of Technology, Chemical Engineering department laboratory.

Preparation of Aloe vera coating solution
Freshly harvested aloe vera leaves was first washed with tap water and then distilled water. The extraction was performed according to the method described by [7]. The lower leaf base, the tapering point of the leaves top and the short, sharp spines located along the leaves margins was first removed by a sharp knife. 


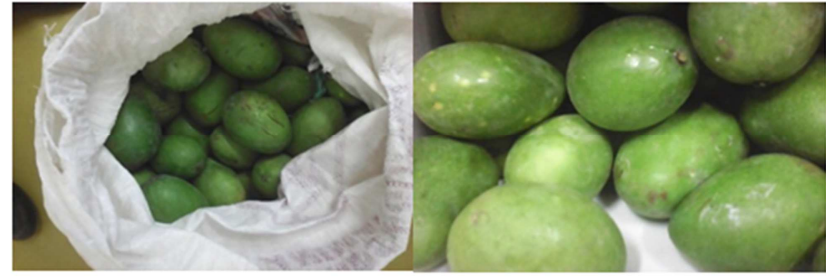

Figure 2. Collected Mango Fruits.

Then the knife was be introduced into the mucilage layer below the green rind avoiding the vascular bundles and the top rind is removed (Figure 3).
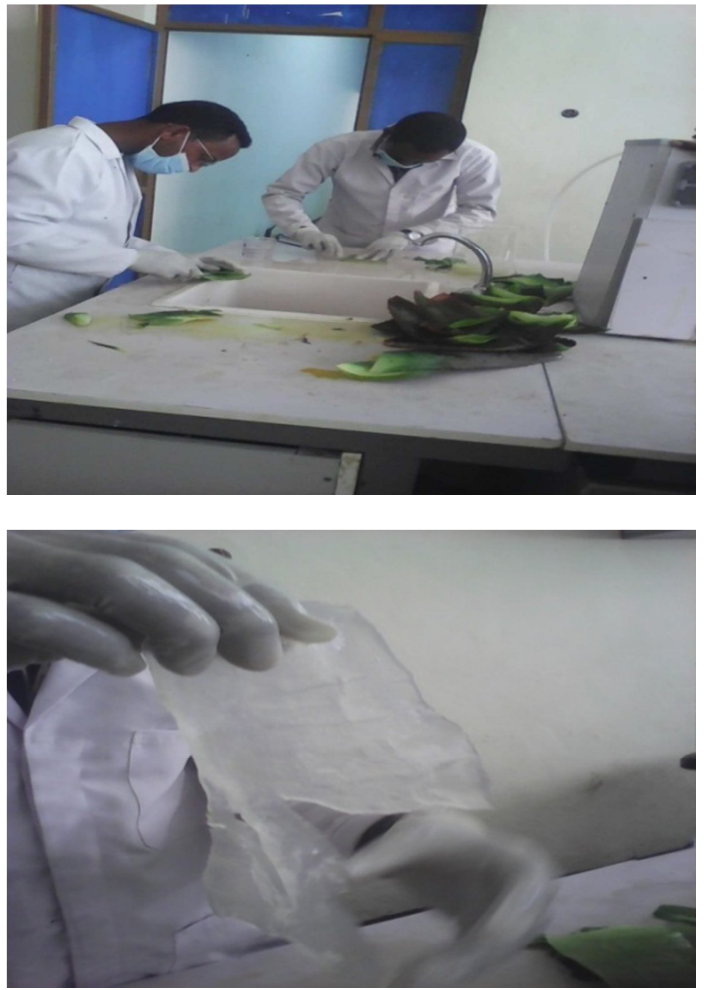

Figure 3. Colorless hydro parenchyma.

The colorless hydro parenchyma obtained was homogenized in to solution using blender at room temperature and the solution was filtered using cheesecloth. The clear aloe extract is susceptible to enzymatic degradation. The extract was stored at $4^{\circ} \mathrm{C}$ until used for further analysis.

\subsection{Experimental Treatments and Design}

The experiment comprised of three treatments viz., control $\left(T_{0}\right)$, aloe vera gel solution $\left(T_{1}\right)$, aloe vera gel with citric acid solution $\left(\mathrm{T}_{2}\right)$. Sources of variation were time of storage and treatments, and the interaction of treatments $\times$ storage time with three replications where physicochemical properties were analyzed at seven days intervals during the storage period.

\subsection{Application of Experimental Treatments}

The fruit was harvested by hand at green stage of maturity, randomly. The fruit was cleaned carefully by washing it with water to remove all foreign matters, such as dust and dirt. Maximum efforts were used to select the fruit uniform in size, good in quality and free from injury or disease. The materials used for coating were Aloe vera gel $\left(\mathrm{T}_{1}\right)$, Aloe vera gel with citric acid $\left(\mathrm{T}_{2}\right)$ and fruit without coating (control, $\left.\mathrm{T}_{0}\right)$ was used.

Cleaned mango fruits were treated with aloe vera gel, aloe vera gel combined with citric acid solution (1\%). Treatments were performed by immersion for 5 min with a solution of aloe vera gel (Figure 4).

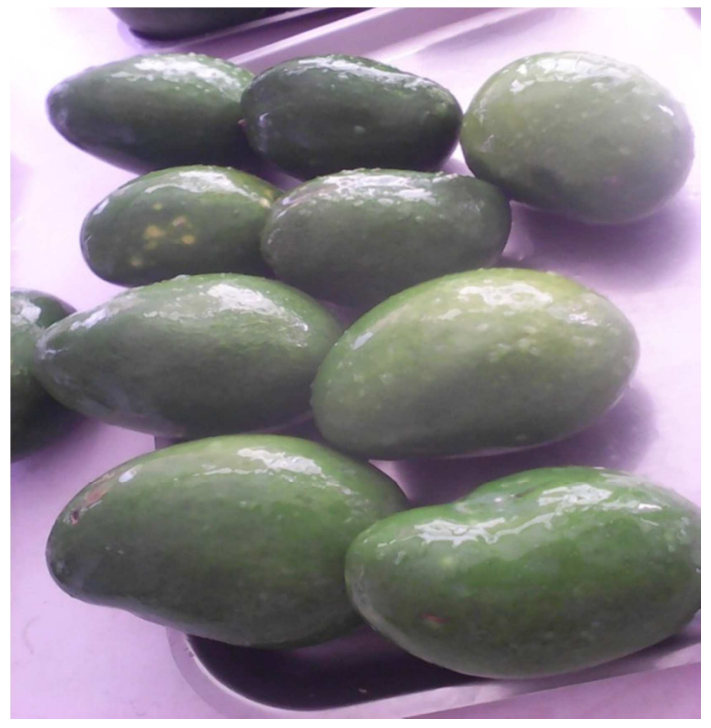

a) coating of mango fruit.

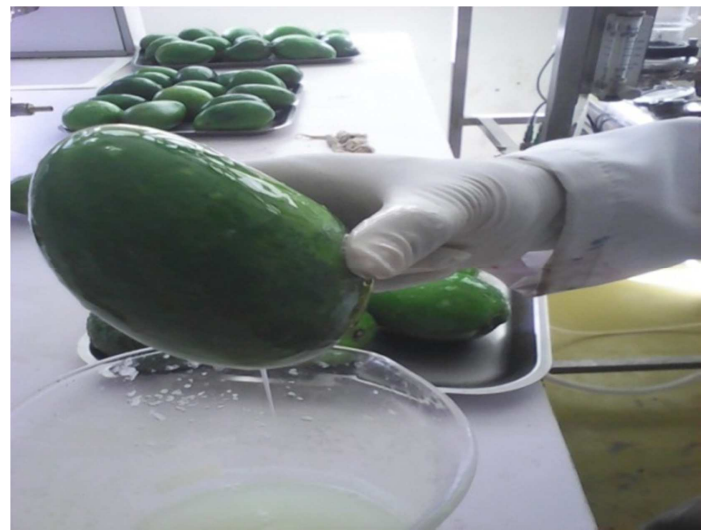

b) coated mango fruit.

Figure 4. Immersion of mango fruits with a solution of aloe vera gel.

Following treatment, all mango fruits were air-dried for 60 min before storage at room temperature for 35 days. There is 3 replications for each treatment both treated and control fruits will be taken after $0,7,14,21,28$, and 35 days; for quality evaluation like weight loss, $\mathrm{P}^{\mathrm{H}}$ of fruit juice, total soluble solids, titratable acidity, soluble solid contents.

\subsection{Statistical Analysis}

The collected data on various parameters obtained from the experiment was subjected to appropriate statistical tools 
of JMP version 5 (SAS Institute Inc., Cary, NC, USA). Sources of variation were time of storage and treatments, and the interaction of treatments $\times$ storage time. Comparisons between sample treatments were done using analysis of variance (ANOVA). Student's t -test was used to identify significant differences by comparing means for processing method. Accordingly, ANOVA, mean comparison and significance were set at 5\% level.

\section{Result and Discussion}

\subsection{Effect of Coating on Fruit Weight Loss}

Table 1 shows the weight loss of mature mango fruits surface-coated with aloe vera gel and stored for different periods of time (0-35 days) at room temperature. All samples demonstrated a gradual loss of weight during storage. Weight loss mainly occurs due to water loss by transpiration and loss of carbon reserves due to respiration. The rate at which water is lost depends on the water pressure gradient between the fruit tissue and the surrounding atmosphere. Aloe gel based edible coating act as barrier, thereby restricting water transfer and protecting fruit skin from mechanical injuries.

Throughout storage, the weight loss of uncoated fruit (sample) was significantly greater than that of Aloe gel coated fruit. At the end of the storage, uncoated mango showed $22.04 \%$ loss in weight, whereas the weight losses of samples coated with Aloe vera gel was $8.6 \%$ and with aloe vera with citric acid coated fruit samples shows a $7.6 \%$ weight loss. This positive effect in terms of reduction of moisture loss may be due to the hygroscopic properties of Aloe gel that allow the formation of water barrier between the fruit and the surrounding environment. Thus, preventing its external transferences [6]. Additionally, Aloe vera gel mostly composed of polysaccharide which is highly effective as a barrier against moisture loss without incorporation of lipid. Similar reductions in weight loss have been reported in Aloe vera coated sweet cherry and table grapes [4].

\subsection{Effect of Coating on Moisture Loss}

The results indicate that the moisture content was gradually decreased during the storage period. The moisture content was higher in control mango compared to aloe vera gel, aloe vera with citric acid treatment (Table 1). The decrease in moisture content during storage was also reported by [11]. The decrease of moisture content was probably due to transpiration and evaporation loss and also due to starch hydrolysis.

Table 1. Effects of aloe vera coating on weight loss and moisture content of mango fruits.

\begin{tabular}{|c|c|c|c|c|c|c|}
\hline \multirow{2}{*}{ Storage time } & \multicolumn{3}{|c|}{ Weight loss (\%) } & \multicolumn{3}{|c|}{ Moisture Loss (\%) } \\
\hline & $\mathbf{T}_{0}$ & $\mathbf{T}_{1}$ & $\mathbf{T}_{2}$ & $\mathbf{T}_{\mathbf{0}}$ & $\mathrm{T}_{1}$ & $\mathbf{T}_{2}$ \\
\hline ODAS & $231.5 \pm 0.7^{\mathrm{a}}$ & $349.41 \pm 0.4^{\mathrm{b}}$ & $258.1 \pm 0.3^{\mathrm{c}}$ & $68.13 \pm 0.2^{\mathrm{a}}$ & $69.4 \pm 0.1^{\mathrm{b}}$ & $68.47 \pm 0.2^{\mathrm{a}}$ \\
\hline 7DAS & $210.1 \pm 0.11^{\mathrm{a}}$ & $322.4 \pm 0.1^{\mathrm{b}}$ & $251.5 \pm 0.2^{c}$ & $58.47 \pm 1.36^{\mathrm{a}}$ & $65.4 \pm 0.1^{\mathrm{b}}$ & $65.8 \pm 0.6^{\mathrm{b}}$ \\
\hline 14DAS & $190.17 \pm 0.2^{\mathrm{a}}$ & $336.92 \pm 0.6^{b}$ & $246.4 \pm 0.4^{\mathrm{c}}$ & $47.67 \pm 0.15^{\mathrm{a}}$ & $60.87 \pm 0.06^{\mathrm{b}}$ & $61.9 \pm 0.36^{\mathrm{c}}$ \\
\hline 21DAS & $180.47 \pm 0.6^{\mathrm{a}}$ & $319.46 \pm 1.8^{b}$ & $241.43 \pm 0.5^{\mathrm{c}}$ & $42.8 \pm 0.1^{\mathrm{a}}$ & $59.1 \pm 0.7^{\mathrm{b}}$ & $59.3 \pm 0.7^{\mathrm{b}}$ \\
\hline 28DAS & - & $280.1 \pm 0.1^{\mathrm{a}}$ & $238.4 \pm 0.0^{\mathrm{b}}$ & - & $56.4 \pm 0.2^{\mathrm{a}}$ & $55.1 \pm 0.2^{\mathrm{b}}$ \\
\hline
\end{tabular}

Where $\mathrm{T}_{0}$-control, $\mathrm{T}_{1}$-alovera gel, $\mathrm{T}_{2}$-aloevera with citric acid, DAS- Days after storage, Values in the same row (control and coated) not connected with same letter are significantly different. Values are mean and $\mathrm{SD}$ of three separate determinations.

\subsection{Effect of Coating on PH Values}

There is an increment of the $\mathrm{P}^{\mathrm{H}}$ values throughout the storage time (Table 2). $\mathrm{P}^{\mathrm{H}}$ value of control at the time of storage on the 21 th day was 5.21 , whereas for aloe vera gel coated fruit it was 4.31 and aloe vera with citric acid storage
3.89. The increase in $\mathrm{pH}$ value may be due to break-up of acids with respiration during storage. The $\mathrm{pH}$ value of aloe vera gel coated fruit and aloe vera with citric acid coated fruit was increased to 5.21 and 4.96, respectively, during storage on the $28^{\text {th }}$ day.

Table 2. Effects of aloe vera coating on pH of mango fruits.

\begin{tabular}{llll}
\hline \multirow{2}{*}{ Storage Time } & $\mathbf{p H}$ value & & \\
\cline { 2 - 4 } & $\mathbf{T}_{\mathbf{0}}$ & $\mathbf{T}_{\mathbf{1}}$ & $\mathbf{T}_{\mathbf{2}}$ \\
\hline 0DAS & $3.14 \pm 0.02^{\mathrm{a}}$ & $3.26 \pm 0.01^{\mathrm{b}}$ & $3.62 \pm 0.0^{\mathrm{c}}$ \\
7DAS & $3.28 \pm 0.0^{\mathrm{a}}$ & $3.88 \pm 0.01^{\mathrm{b}}$ & $3.77 \pm 0.01^{\mathrm{c}}$ \\
14DAS & $4.47 \pm 0.06^{\mathrm{a}}$ & $3.98 \pm 0.0^{\mathrm{b}}$ & $3.79 \pm 0.01^{\mathrm{c}}$ \\
21DAS & $5.21 \pm 0.01^{\mathrm{a}}$ & $4.31 \pm 0.01^{\mathrm{b}}$ & $3.89 \pm 0.08^{\mathrm{c}}$ \\
28DAS & - & $5.21 \pm 0.01^{\mathrm{a}}$ & $4.96 \pm 0.0^{\mathrm{b}}$ \\
\hline
\end{tabular}

Where $\mathrm{T}_{0}$-control, $\mathrm{T}_{1}$-alovera gel, $\mathrm{T}_{2}$-aloevera with citric acid, DAS- Days after storage, Values in the same row (control and coated) not connected with same letter are significantly different. Values are mean and SD of three separate determinations.

\subsection{Effect of Coating on Total Soluble Solid}

Aloe vera gel treated fruits showed a lower increase (Table 3) in TSS (Total Soluble Solid), which indicated that control fruits presented a more pronounced maturation development than coated berries during storage periods. The increase in TSS of control mango was mainly due to the progressive boost in free sugars of mango during storage periods.

In case of Aloe vera with citric acid coated fruits, decrease TSS content of fruits during storage periods. This is due to 
the value of ascorbic acid content for coated mango fruits were found to be higher than that of uncoated fruits. Similarly, [1], found that ascorbic acid content was higher in Aloe coated papaya fruits than the control fruits during the storage period at temperatures $25^{\circ} \mathrm{C}-29^{\circ} \mathrm{C}$ and $82-84 \% \mathrm{RH}$.
Citric acid coated mango retarded TSS development because aloe gel decreases the respiration and eventually matabolism of sugars. This may be due to the effect of aloe vera gel coating on the reduction of $\alpha$-galactosidase, polygalacturonase and pectinmethylesterase activities.

Table 3. Effects of aloe vera coating on TSS mango fruits.

\begin{tabular}{lllll}
\hline \multirow{2}{*}{ Treatment } & TSS (\%) & & & \\
\cline { 2 - 5 } & ODAS & 7DAS & 14DAS & 210 DS \\
\hline To & $18.18 \pm 0.06^{\mathrm{a}}$ & $19.48 \pm 0.54^{\mathrm{a}}$ & $24.0 \pm 0.18^{\mathrm{a}}$ & $26.6 \pm 0.42^{\mathrm{a}}$ \\
T1 & $18.31 \pm 0.09^{\mathrm{a}}$ & $19.33 \pm 0.076^{\mathrm{a}}$ & $22.34 \pm 0.19^{\mathrm{B}}$ & $23.8 \pm 0.0^{\mathrm{a}}$ \\
T2 & $17.91 \pm 0.5^{\mathrm{a}}$ & $19.17 \pm 0.06^{\mathrm{a}}$ & $21.75 \pm 0.07^{\mathrm{C}}$ & $22.62 \pm 0.28^{\mathrm{a}}$ \\
\hline
\end{tabular}

Where $\mathrm{T}_{0}$-control, $\mathrm{T}_{1}$-alovera gel, $\mathrm{T}_{2}$-aloevera with citric acid, DAS- Days after storage, Values in the same column (control and coated) not connected with same letter are significantly different. Values are mean and SD of three separate determinations.

The results revealed that surface coating produced an effective semipermeable film around the fruit and modified the internal atmosphere of fruit by reducing $\mathrm{O}_{2}$ and/or elevating $\mathrm{CO}_{2}$ and reducing the production of ethylene. Decrease in TSS of coated fruit had a direct relation to the aloe vera solution used for coating. Lower rates of respiration also reduce the synthesis and utilization of metabolites that result in lower TSS [13]. Furthermore, the reduction of TSS during storage is generally due to sugar-acid metabolism.

\subsection{Effect of Coating on Titratable Acidity}

The values for TA of coated and uncoated fruit during storage were found to decrease with storage time (Table 4), and the rate of decline was significantly higher for the control fruits than for coated ones. The low level of TA in the control fruits compared with surface coated fruits shows that aloe vera coating prevented further ripening by creating a semi permeable film around the fruit. This retention of TA content by coated mango was due to the protective effect of aloe gel coating as a barrier to $\mathrm{O}_{2}$ from the surrounding atmosphere and reduction of respiration [12].

It has been also reported that the TA values of coated and uncoated mature green fruit of tomato during storage decreased with storage time, and the values were coating can reduce the respiration rate and may therefore prevent or delay the consumption of organic acids in respiration [13].

Table 4. Effects of aloe vera coating on TA mango fruits.

\begin{tabular}{lllll}
\hline \multirow{2}{*}{ Treatment } & TA $(\%)$ & & \\
\cline { 2 - 5 } & ODAS & 7DAS & 14DAS & 21DAS \\
\hline To & $0.606 \pm 0.02^{\mathrm{a}}$ & $0.607 \pm 0.01^{\mathrm{a}}$ & $0.53 \pm 0.01^{\mathrm{a}}$ & $0.42 \pm 0.01^{\mathrm{a}}$ \\
T1 & $0.573 \pm 0.0^{\mathrm{b}}$ & $0.573 \pm 0.0^{\mathrm{b}}$ & $0.527 \pm 0.0^{\mathrm{a}}$ & $0.46 \pm 0.0^{\mathrm{b}}$ \\
T2 & $0.59 \pm 0.0^{\mathrm{b}}$ & $0.587 \pm 0.02^{\mathrm{b}}$ & $0.54 \pm 0.01^{\mathrm{a}}$ & $0.47 \pm 0.01^{\mathrm{C}}$ \\
\hline
\end{tabular}

Where $\mathrm{T}_{0}$-control, $\mathrm{T}_{1}$-alovera gel, $\mathrm{T}_{2}$-aloevera with citric acid, DAS- Days after storage, Values in the same column (control and coated) not connected with same letter are significantly different. Values are mean and SD of three separate determinations.

\subsection{Effect of Coating on Shelf life of Mango Fruits}

In general, the results showed that the application of aloe vera coating with citric acid solution shows a longer storage time than control fruits. Aloe vera jel had an impact to extend the postharvest quality parameters during storage time. The control fruits started deteriorated before 17 days and only few fruits survived up to 21 days, whereas, shelf life extended to 29 days for majority of aloe vera gel alone and with citric acid. This could be attributed to the delayed ripening process. In climacteric fruits like mango, an increase in ethylene production during ripening is a normal physiological process. Reduction of ethylene production was higher in aloe vera gel with citric acid coated mango than aloe vera gel coated mango and control mango fruits.

\section{Conclusion}

The application of coatings using this naturally available organic resources like aloe vera could easily be integrated in the current handling system of fruit and would provide additional shelf-life benefits to the fruit. Comparing with the uncoated mango fruits, all the coated fruits showed significantly reduced weight loss and delayed changes in the ripening parameters such as TSS, TA and \% moisture loss levels $(\mathrm{p} \leq 0.05)$. In addition, the aloe vera treatments combined with citric acid (1\%) led to rachises with better freshness without browning symptoms after 21 days of storage.

This work assures that aloe vera gel coating as a successful bio-preservative and a useful alternative to synthetic preservative. To effectively extend the shelf life of postharvest fruits, aloe vera gel based coating as a relatively convenient and safe measure. Aloe vera based coating is totally harmless to the environment. In fact it can be considered as a green alternative to synthetic coatings and other postharvest chemical treatments.

Dipping into an Aloe vera extract and combining with citric acid allowed to reduce the respiration rate of mango fruit and was effective at reducing the enzymatic activities commonly considered as responsible for the quality decay. 
Also, the general aspect and browning extent confirmed the ability of mango coating with aloe vera combined with citric acid to maintain better quality for at least 21 days compared to untreated mango fruits.

\section{References}

[1] Brishti, F. H., Misir, J. and Sarker, A. 2013. Effect of biopreservatives on storage life of papaya fruit (Carica Papaya L). Int. J. Food Studies, 2(1): 126-136.

[2] Castillo, S., Navarro, D., Zapata, P. J., Guillen, F., Valero, M., Serrano, D. and Martinez-Romero, (2010). "Antifungal efficacy of Aloe vera in vitro and its use as a postharvest treatment to maintain postharvest table grape quality", Postharvest Biology and Technology, 57 (3). 183-188.

[3] Lin, D. and Zhao, Y. 2007, "Innovations in the development and application of edible coatings for fresh and minimally processed fruits and vegetables", Comprehensive Reviews in Food Science and Food Safety-CRFSFS, 6 (3). 60-75. 2007.

[4] Martínez-Romero, D., N. Alburquerque, J. Valverde, F. Guillén, S. Castillo, D. Valero and M. Serrano, (2006). Postharvest sweet cherry quality and safety maintenance by Aloe vera treatment: A new edible coating. Postharvest Biology and Technology, 39(1): 93-100

[5] Mchugh, T. H. and Senesi, E., (2000). "Apple wraps: A novel method to improve the quality and extend the shelf life of fresh-cut apples", Journal of Food Science, 65 (3). 480-485.

[6] Morillon, V., Debeaufort, F., Blond, G., Capelle, M., \&Voilley, A., (2002). "Factors affecting the moisture permeability of lipid-based edible films: A review", Critical Reviews in Food Science and Nutrition, 42 (1). 67-89.

[7] Ramachandra and P. SrinivasaRao. (2008). Processing of Aloe Vera Leaf Gel: A Review, American Journal of Agricultural and Biological Sciences, Volume 3, Issue 2, 502-510.

[8] Rojas-Argudo, C., M. B. Perez-Gago and M. Del Río, (2005). Postharvest quality of coated cherries cv. 'Burlat'as affected by coating composition and solids content. Food science and technology international, 11(6): 417-424.

[9] Sardsud, V., U. Sardsud, P. Chantrasri and S. Pasatketkorn, (2003). Alternative postharvest treatments on longan fruits for replacement of sulfur dioxide fumigation. Agricultural Science Journal, 33: 243-246.

[10] Serrano, M, Valverde, J., Guillen, F, Castillo, S, MartinezRomero, D, \& Valero, D., (2006). "Use of Aloe vera gel coating preserves the functional properties of table Grapes", Journal of Agricultural and Food Chemistry, 54 (11). 38823886 .

[11] Sharmin M. R, M. N. Islam and M. A. Alim (2015). Shelf-life enhancement of papaya with aloe vera gel coating at ambient temperature, J. Bangladesh Agril. Univ. 13(1): 131-136, 2015.

[12] Srinu, B., Vikram, K. B., Rao, L. V., Kalakumar, B., Rao, T. M. and Reddy, A. G. (2012). Screening of antimicrobial activity of Withaniasomnifera and Aloe vera plant extracts against food borne pathogens. J. Chem. Pharma. Research, 4(11): 4800-4803.

[13] Yaman, O. and Bayoindirli, L. (2002). Effects of an edible coating and cold storage on shelf-life and quality of cherries. Lebnsm. -Wiss. Technol. 35, 146-150. 